Original Article

\title{
Effects of the Schroth exercise on the Cobb's angle and vital capacity of patients with idiopathic scoliosis that is an operative indication
}

\author{
Kyoung-Don Kim, PhD, PT ${ }^{1)}$, Pil-Neo Hwangbo, PhD, $\mathrm{PT}^{2)^{*}}$ \\ 1) Daegu Fatima Hospital, Republic of Korea \\ 2) Department of Physical Therapy, Graduate School of Physical Therapy, Daegu University: Naeri-ri, \\ Jillyang, Gyeongsan-si, Gyeongsangbuk-do, Republic of Korea
}

\begin{abstract}
Purpose] The purpose of this study was to investigate the effects of the Schroth exercise on the Cobb's angle and vital capacity of patients with growing idiopathic scoliosis, an operative indication. [Subjects] Five idiopathic scoliosis patients with a Cobb's angle of the thoracic vertebra of 40 degrees or higher and Risser sign stage 3 or higher. [Methods] The Schroth exercise was applied 3 times a week for 12 weeks. We measured the thoracic trunk inclination, Cobb's angle, and vital capacity before and after the exercise program. [Results] The thoracic trunk rotation angle decreased from $11.86 \pm 3.32^{\circ}$ to $4.90 \pm 1.91^{\circ}$ on average, the thoracic Cobb's angle decreased from $42.40 \pm 7.86^{\circ}$ to $26.0 \pm 3.65^{\circ}$ on average, and the vital capacity also increased from $2.83 \pm 1.23^{\circ}$ to $4.04^{\circ} \pm 1.67^{\circ}$ on average. All these effects were significant. [Conclusion] The 12-week Schroth exercise caused significant effects in the thoracic trunk inclination, Cobb's angle, and vital capacity. The conservative treatment method was found to be effective even at a 40 degree or higher Cobb's angle. In the future, universal exercise approach methods and preventive training for the treatment of scoliosis should be developed further.

Key words: Schroth exercise, Cobb's angle, Scoliosis
\end{abstract}

(This article was submitted Oct. 23, 2015, and was accepted Dec. 12, 2015)

\section{INTRODUCTION}

Scoliosis refers to a 3-dimensional deformation of the natural bending of the spine ${ }^{1)}$. In the clinical setting, the Cobb's angle analysis method, which is a valid analysis of the size of the lateral bending through radiographic methods, is generally used $^{2)}$. Minor scoliosis with less than a $20^{\circ}$ Cobb's angle requires periodic observation, and scoliosis with a Cobb's angle of $20-40^{\circ}$ requires the wearing of an orthosis to prevent progress. If the Cobb's angle is greater than $40^{\circ}$, it indicates the need of surgery ${ }^{3}$. If scoliosis is detected and treated early, most patients do not need surgical treatment ${ }^{4}$; ; in some cases, surgical treatment may have poorer results ${ }^{5}$. The orthosis treatment, which is the first stage of scoliosis treatment, can cause spondylosis and loss of the surrounding muscles ${ }^{6}$. If this limitation of normal movement occurs in growing adolescents, it could cause undesirable results ${ }^{7}$. Scoliosis causes deformations of the spinal column and structures ${ }^{8)}$, decreases in spinal flexibility by changing the characteristics of the erector spinae muscle ${ }^{9}$, and leads to imbalances of the trunk and pelvis depending on the shape and angle of the scoliosis ${ }^{10)}$. Furthermore, it has been reported that correction and respiratory treatment are essential because of the bending of the thoracic cage, which weakens the respiratory muscle and lowers cardiopulmonary function ${ }^{11)}$. Various core and breathing exercises are used to treat scoliosis ${ }^{12,13}$. The treatment effects of the Schroth therapy, a recent therapeutic exercise, have been reported ${ }^{14,15)}$. Often referred to as a 3-dimensional therapy, the Schroth exercise improves the trunk shape and respiratory ability by applying "rotational breathing"16), and it has been reported to improve the function of the thoracic wall and the symptoms of the respiratory system ${ }^{17)}$. Many studies have investigated the improvement effects

\footnotetext{
*Corresponding author. Pil-Neo Hwangbo (E-mail: pt486pn@naver.com)

(C)2016 The Society of Physical Therapy Science. Published by IPEC Inc.

This is an open-access article distributed under the terms of the Creative Commons Attribution Non-Commercial No Derivatives (by-nc-nd) License $<$ http://creativecommons.org/licenses/by-nc-nd/4.0/>.
} 
of the Schroth exercise on Cobb's angle and vital capacity in scoliosis patients, but most studies were on patients whose Cobb's angle was smaller than $30^{\circ}$ or the studies combined the Schroth exercise with orthosis treatment. Studies on subjects with a $40^{\circ}$ or higher Cobb's angle who require surgery are still insufficient. Therefore, this study investigated the effects of the Schroth exercise therapy in patients with scoliosis as a surgical indication for the improvement of their Cobb's angle and vital capacity.

\section{SUBJECTS AND METHODS}

The subjects in this study were 5 female students among patients with thoracic scoliosis whose Cobb's angle was greater than $40^{\circ}$ and whose Risser sign was stage 3 or higher treated at N Hospital in Daegu, South Korea (Table 1). Every subject was explained the purpose of this study and the exercise method and voluntarily signed the informed consent form before participating in this experiment, according to the ethical standards of the Declaration of Helsinki. We excluded individuals who had neurological findings or an operation, who recently received surgical treatment, who wore an orthosis, or who were periodically taking medicine from our study. Subjects performed the Schroth exercise 3 times a week for 12 weeks. Each 60-minute session consisted of preparation (cat walking and breathing exercise: $10 \mathrm{~min}$ ), stretching (stretching the chest part: $5 \mathrm{~min}$ ), the main exercise (laying right click concave, laying aside static postural control training, sitting posture adjustment exercise, and muscle cylinder: $40 \mathrm{~min}$ ), and wrap-up (moving ribs: $5 \mathrm{~min}$ ). We applied the Schroth exercise in accordance with the bending shape of each subject, along with 3-dimensional Schroth rotational breathing ${ }^{18)}$. We measured Cobb's angle, with the patient standing straight, using a radiography apparatus (CR 85-X, USA). The trunk rotation angle was measured through the Adam's forward bending test using a scoliometer (OSI, USA). The vital capacity was measured 3 times after 3 or more breathing exercises in a $90^{\circ}$ sitting position using CardioTouch 3000S (BIONET, Korea); we recorded the average values. To compare the changes in Cobb's angle, thoracic trunk rotation angle, and vital capacity after the Schroth exercise, we analyzed the data using SPSS 18.0. We used a 1-sample paired t-test with a significance level of $\mathrm{p}<0.05$.

\section{RESULTS}

The patients in our study had a thoracic trunk rotation angle decrease from $11.86 \pm 3.32^{\circ}$ to $4.90 \pm 1.91^{\circ}$ on average, Cobb's angle decrease from $42.40 \pm 7.86^{\circ}$ to $26.00 \pm 3.65^{\circ}$ on average, and vital capacity increase from $2.83 \pm 1.231$ to 4.04 \pm 1.671 on average. All these effects were statistically significant $(\mathrm{p}<0.05$; Table 2$)$.

\section{DISCUSSION}

In this study, to examine the effects of the Schroth exercise on Cobb's angle, thoracic trunk rotation angle, and vital capacity of patients with scoliosis as a surgical indication, the subjects performed the Schroth exercise 3 times a week for 12 weeks.

The Schroth exercise has the advantage of correcting the posture according to the bending type and is an effective mechanism to facilitate the correction of posture in the 3 dimensions of scoliosis ${ }^{19}$. The Schroth 3-dimensional rotational breathing exercise induces significant increases in rib movements and vital capacity and induces a significant increase in the sagittal breathing exercise for the improvement of flat back ${ }^{20)}$. Furthermore, the Schroth 3-dimensional exercise approach has been

Table 1. General characteristics of the subjects

\begin{tabular}{lc}
\hline & $\mathrm{N}=10$ (Female: 6$)$ \\
\hline Age (years) & $22.60 \pm 1.83$ \\
Height $(\mathrm{cm})$ & $167.00 \pm 7.45$ \\
Weight $(\mathrm{kg})$ & $63.80 \pm 12.01$ \\
Cobb's angle $\left(^{\circ}\right)$ & $17.03 \pm 0.54$ \\
Risser sign (phase) & $3.23 \pm 1.04$ \\
\hline \multicolumn{2}{l}{ Mean \pm SD: mean \pm standard deviation }
\end{tabular}

Table 2. Pre- and post-intervention comparisons (Unit: ratio)

\begin{tabular}{lcc}
\hline & Pre-test & \multicolumn{1}{c}{ Post-test } \\
\hline Trunk rotation angle $\left(^{\circ}\right)$ & $11.86 \pm 3.32$ & $4.90 \pm 1.91^{*}$ \\
Cobb's angle $\left(^{\circ}\right)$ & $42.40 \pm 7.86$ & $26.00 \pm 3.65^{*}$ \\
Vital capacity $(1)$ & $2.83 \pm 1.23$ & $4.04 \pm 1.67^{*}$ \\
\hline
\end{tabular}

Mean \pm SE, *Significant difference from pre-test, $\mathrm{p}<0.05$ 
proven to decrease the progress of idiopathic scoliosis, improve Cobb's angle and resolve pain ${ }^{21,22)}$, and reduce the prescription of orthosis ${ }^{23}$. Borysov et al. measured Cobb's angle with a scoliometer after applying the Schroth exercise, which significantly decreased from $8.9^{\circ}$ to $6.5^{\circ 24}$. Otman et al. reported that the Schroth exercise showed significant effects not only on Cobb's angle but also on vital capacity ${ }^{15)}$. After the Schroth exercise, pain due to scoliosis resolved or improved in $85 \%$ of the patients, which helped enhance their quality of life ${ }^{25)}$, and the vital capacity increased in roughly $95 \%$ of the patients. The vital capacity increased by at least $600 \mathrm{ml}$ in $22 \%$ of the patients after 6 weeks and by $800 \mathrm{ml}$ in $11 \%$ of the patients after the same period ${ }^{26)}$. The results of the present study also showed significant effects in the thoracic Cobb's angle, thoracic trunk rotation angle, and vital capacity after the Schroth exercise. The trunk rotation angle decreased when the acromion of the rib was turned to the opposite side by the 3-dimensional rotational breathing during the Schroth exercise. This 3-dimensional rotational breathing allowed the exercise to become more 3-dimensional, which expanded the narrowed thoracic cage. Furthermore, with the use of the forced inspiratory and the forced expiratory muscles, the angle of scoliosis and pulmonary function decreased simultaneously. Therefore, this study showed that the Schroth exercise, which is a conservative therapy, was effective even for subjects with a $40^{\circ}$ or greater Cobb's angle who need operative treatment. Growing adolescents have a high risk of progress owing to a high degree of scoliosis because they spend much time sitting at school. Therefore, appropriate education, prevention, and improvement of scoliosis are necessary. In addition to this, universal exercises and preventive education need to be more advanced than they are now.

Limitations of this study include the limited number of patients with $40^{\circ}$ or greater scoliosis and the difficulty in finding time for the subjects to participate in this study because most were students who had to attend school. In the future, a study comparing the effects with a group among whom the Schroth exercise is combined with orthosis treatment will be necessary.

\section{REFERENCES}

1) Benameur $S$, Mignotte $M$, Parent $S$, et al.: $3 D / 2 D$ registration and segmentation of scoliotic vertebrae using statistical models. Comput Med Imaging Graph, 2003, 27: 321-337. [Medline] [CrossRef]

2) Cassar-Pullicino VN, Eisenstein SM: Imaging in scoliosis: what, why and how? Clin Radiol, 2002, 57: 543-562. [Medline] [CrossRef]

3) Roach JW: Adolescent idiopathic scoliosis. Orthop Clin North Am, 1999, 30: 353-365, vii-viii vii-viii. [Medline] [CrossRef]

4) Landauer F, Wimmer C, Behensky H: Estimating the final outcome of brace treatment for idiopathic thoracic scoliosis at 6-month follow-up. Pediatr Rehabil, 2003, 6: 201-207. [Medline]

5) Weiss HR: Adolescent Idiopathic Scoliosis - case report of a patient with clinical deterioration after surgery. Patient Saf Surg, 2007, 1: 7. [Medline] [CrossRef]

6) Kotwicki T, Napiontek M: Intravertebral deformation in idiopathic scoliosis: a transverse plane computer tomographic study. J Pediatr Orthop, 2008, 28: 225-229. [Medline] [CrossRef]

7) Mahaudens $P$, Banse X, Mousny M, et al.: Very short-term effect of brace wearing on gait in adolescent idiopathic scoliosis girls. Eur Spine J, 2013, 22: 2399-2406. [Medline] [CrossRef]

8) Zabjek KF, Leroux MA, Coillard C, et al.: Acute postural adaptations induced by a shoe lift in idiopathic scoliosis patients. Eur Spine J, 2001, 10: 107-113. [Medline] [CrossRef]

9) Trobisch P, Suess O, Schwab F: Idiopathic scoliosis. Dtsch Arztebl Int, 2010, 107: 875-883, quiz 884. [Medline]

10) Park JY, Park GD, Lee SG, et al.: The effect of scoliosis angle on center of gravity sway. J Phys Ther Sci, 2013, 25: 1629-1631. [Medline] [CrossRef]

11) Lonstein JE: Adolescent idiopathic scoliosis. Lancet, 1994, 344: 1407-1412. [Medline] [CrossRef]

12) Kim JJ, Song GB, Park EC: Effects of Swiss ball exercise and resistance exercise on respiratory function and trunk control ability in patients with scoliosis. J Phys Ther Sci, 2015, 27: 1775-1778. [Medline] [CrossRef]

13) Lee MG, Hwang JS, Seo BD, et al.: The effects of the core muscle release technique on scoliosis. J Phys Ther Sci, 2013, 25: 445-448. [CrossRef]

14) Yang JM, Lee JH, Lee DH: Effects of consecutive application of stretching, Schroth, and strengthening exercises on Cobb's angle and the rib hump in an adult with idiopathic scoliosis. J Phys Ther Sci, 2015, 27: 2667-2669. [Medline] [CrossRef]

15) Otman S, Kose N, Yakut Y: The efficacy of Schroth's 3-dimensional exercise therapy in the treatment of adolescent idiopathic scoliosis in Turkey. Neurosci Riyadh, 2005, 10: 277-283. [Medline]

16) Rigo M, Quera-Salvá G, Villagrasa M, et al.: Scoliosis intensive out-patient rehabilitation based on Schroth method. Stud Health Technol Inform, 2008, 135: 208-227. [Medline] 
17) Brooks WJ, Krupinski EA, Hawes MC: Reversal of childhood idiopathic scoliosis in an adult, without surgery: a case report and literature review. Scoliosis, 2009, 4: 27. [Medline] [CrossRef]

18) Kim BJ: A Comparison on the Influences of Schroth-based Static Scoliosis Exercise and Asymmetric Scoliosis Exercise on the Patients with Scoliosis. Graduate School of Daegu University, PhD thesis, 2014.

19) Negrini S, Antonini G, Carabalona R, et al.: Physical exercises as a treatment for adolescent idiopathic scoliosis. A systematic review. Pediatr Rehabil, 2003, 6: 227-235. [Medline]

20) Weiss HR: The effect of an exercise program on vital capacity and rib mobility in patients with idiopathic scoliosis. Spine, 1991, 16: 88-93. [Medline] [CrossRef]

21) Fusco C, Zaina F, Atanasio S, et al.: Physical exercises in the treatment of adolescent idiopathic scoliosis: an updated systematic review. Physiother Theory Pract, 2011, 27: 80-114. [Medline] [CrossRef]

22) Weiss HR: "Brace technology" thematic series - the Gensingen brace ${ }^{\mathrm{TM}}$ in the treatment of scoliosis. Scoliosis, 2010, 5: 22. [Medline] [CrossRef]

23) Negrini S, Fusco C, Minozzi S, et al.: Exercises reduce the progression rate of adolescent idiopathic scoliosis: results of a comprehensive systematic review of the literature. Disabil Rehabil, 2008, 30: 772-785. [Medline] [CrossRef]

24) Borysov M, Borysov A: Scoliosis short-term rehabilitation (SSTR) according to 'Best Practice' standards-are the results repeatable? Scoliosis, 2012, 7: 1. [Medline] [CrossRef]

25) Lehnert-Schroth C: Three dimensional treatment for scoliosis: a physiotherapeutic method for deformities of the spine. Seoul: Yeong Mun Publishing Company, 2010.

26) Lehnert-Schroth C: Three-dimensional Treatment for Scoliosis: Physiotherapeutic Method for Deformities of the Spine. New York: Martindale Press, 2007. 